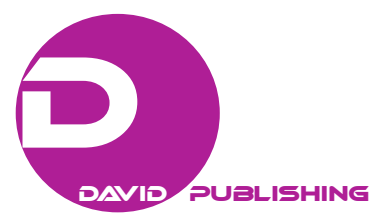

\title{
Institutionalizing Political Monitoring as Part of Policy Design
}

\author{
Thomas D. Lancaster \\ Emory University, Atlanta, USA
}

\begin{abstract}
Building upon previous work (Lancaster, 2014) which defined and theoretically situated political monitoring as an analytical concept, this essay first reiterates the importance of political monitoring to the study of institutions of governance and related policy design. The conceptualization of political monitoring builds upon the psychological notion that people change their behavior if they believe someone is watching them. Second, it discusses theoretically how and why policy design might incorporate political monitoring in order to produce specific outcomes. Third, it presents empirical evidence from several illustrative examples to demonstrate how the institutionalization of political monitoring affects policy outcomes.
\end{abstract}

Keywords: political monitoring, institutionalization, policy design

\section{Introduction}

As a simple psychologically-based concept, the use of "monitoring" asks do people tend to behave differently if they are being watched, or believe someone else is observing them (Lancaster, 2014). Among other lines of inquiry, the concept plays a salient role in explanations of how we overcome "social dilemmas" such as the tragedy of the commons, the prisoner's dilemma, and other types of collective action problems, e.g., principal-agent relations (Ostrom, 1990). More broadly, "political monitoring" directly impacts the pursuit of "good governance" (Norris, 2012) especially when it is effective in changing individual behavior to achieve desired social outcomes. Despite this, "monitoring" as a concept remains underdeveloped analytically and underutilized in scholarly work to explain social patterns in contemporary politics and public policy. Almost ironically, the "politics of monitoring" increasingly impacts many aspects of everyday life: Governments and employers watch our e-mails, businesses track many aspects of our on-line presence, CTR cameras record many of our public movements, the use of aerial drones push our legal boundaries on privacy rights, and picture-taking technology arms average citizens to help document individuals committing criminal acts and to aid authorities in apprehending them.

Elsewhere I have identified and elaborated upon 12 guidelines for the study of political monitoring (Lancaster, 2014, p. 262). As necessary but not sufficient conditions, these 12 guidelines are all important to consider in any study of design and non-design in policy-making. Monitoring as a concept, and the processes it captures, should not be analytically overlooked in any consideration of policy-making design and non-design. The last three of the twelve are especially relevant here: How the monitoring scheme is institutionalized or designed is critical in affecting outcomes; monitoring becomes political when it involves choice over who, what, and how to monitor; and costs are critical to the institutionalization and politics of monitoring. How and if we choose to institutionalize monitoring is a question of governance and, more specifically, of policy

\footnotetext{
Thomas D. Lancaster, Professor, Department of Political Science, Emory University.
} 
design. Consequently, this paper seeks to emphasize the concept of "political monitoring" and to ask how we should think about it theoretically, analytically, and empirically in the study of policy-making design and non-design.

This paper begins by reiterating the importance of the concept of political monitoring to the study of institutions of governance. Key to this analytical section is bearing in mind the central notion that political monitoring as a concept builds upon the psychological notion that people change their behavior if they believe someone is watching them. Second, the paper discusses the importance of policy design in the institutionalization of political monitoring and gives three examples of creative designs involving monitoring. Third, the paper discusses theoretically how policy design might incorporate political monitoring in order to produce specific outcomes. Toward this end, it presents a two-dimensional theoretical classification schema to enhance our policy design analysis vis-à-vis political monitoring. Fourth, empirical evidence will be presented from three illustrative cases to demonstrate how the institutionalization of political monitoring affects behavioral outcomes. The essay concludes with thoughts regarding the future direction of research in policy design as it increasingly includes the concept of political monitoring.

\section{The Concept of Political Monitoring}

"Monitoring" as a policy-oriented process resides comfortably within a larger basket of concepts such as "accountability", "oversight", "audit", "surveillance" and "control". Unfortunately, these terms are often used interchangeably in policy and related social science literatures. Such confusion is understandable. Even the term's translation into some non-English languages adds to this lack of conceptual clarity, e.g. Überwachen in German and controlar in Spanish. While subtle differences exist, this paper seeks to capture the notion of "watching".

Monitoring in the sense of one "watching" or "observing" the behavior of others carries a strong sense of a desire to "control" the behavior of others by "enforcing" a rule or an agreement. Monitoring as used in this paper captures the notion of someone watching the behavior of another in the context of a game or a collective system (Gardner \& Ostrom, 1991, p. 130) with the goal of holding hold one directly accountable for following the devised set of "appropriate rules" and to insure conformity (Agrawal \& Ostrom, 2006, p. 682). Monitoring in the policy design world should be about making sure others follow the rules and how violators of the rules are noticed. ${ }^{1}$ In a manner consistent with Ostrom's usage (1990), monitoring is related to but is not the same concept as "sanctions".

Interesting in and of itself, monitoring as a concept capturing an act of "watching" is highly relevant to the study of policy-making design because it provides explanation. Monitoring in this sense should thus be thought of as an explanatory variable, independent of the outcome. Key to the logic of thinking here, monitoring affects behavior so it is conceived as an independent variable with individual and group behavior thought of as an outcome or a dependent variable. Salient to the study of policy design, especially when analyzing choice sets of rules, laws, and institutions, the relationship between monitoring (and how we institutionalize it) and behavioral change is a causal one. Acknowledging the possibility that endogeneity can exist in the relationship between monitoring schemes and behavioral outcomes, those interested in the inclusion of monitoring in policy-making design should always remain cognizant of the remarkably simple psychological notion that underpins such

\footnotetext{
${ }^{1}$ Elinor Ostrom insisted that the term "rules" should not be equated with formal laws (Ostrom, 1986, p. 6).
} 
scholarly and policy-oriented work - that people tend to change their behavior when they are being watched, or believe they are being observed.

The politics of monitoring is not the watching itself but how we chose to institute it through design in order to achieve desired behavioral outcomes. Monitoring is part of a structured relationship that involves policy-making strategizing about how to best institutionalize a constraint in order to achieve a desired behavior outcome. Both the choice of the institutional structure to foster constraint and the normative aspect of the desired behavior outcome is what potentially makes monitoring "political". Such thinking is clearly in line with Ostrom's discussion about the need to "... monitor conformity to a set of rules..." (Ostrom, 1990, p. 27).

Another way to look at the adjective "political" when thinking about political monitoring as a concept is to remember related etymology. The English words "politics", "policy", "polity" and "police" all share the same linguistic roots: Latin polĩtia for state and the Greek word politeia for citizenship which, in turn, came from politēs for citizen. Political monitoring as a concept seeks to capture the notion of "citizens watching each other" as well as "citizens watching the state" and "the state watching the citizens". And, such "watching" has as its goal a potential constraining of individual behavior with an eye for a preferred social-collective-outcome.

Besides the adjective "political", policy design regarding political monitoring should also recognize the analytical importance of many other modifying words as it includes this important concept. "Monitoring" as a conceptually rich analytical concept possesses great variation. Such modifying adjectives generally help classify different ways in which monitoring is designed, institutionalized, and structured: "private" versus "public", "formal" versus "informal", "internal" versus "external", "internal" versus "external", and "neutral", "reciprocal", or "mutual" (Lancaster, 2014, p. 253). Since, ipso facto, monitoring involves relationships between a collective's participants, the differentiating terms "top-down" or "bottom-up" also provide a useful way to think about political monitoring since it often involves the use of "accountability" in a principal-agent relationship. Such an analytical lens often helps incorporate the essence of monitoring as watching in order to hold an agent responsible for his or her actions on behalf of the principal. This would also include what might be called "macro-level" policy such as the institutionalization of broader issues of governance such as "democratic accountability" as well as "micro-level" relationships important to public policy regarding specific and often personal principal-agent relations.

\section{Importance of Policy Design in Political Monitoring}

Design for policy-making logically asks questions about institutional choice. There are many definitions of "institutions" in the neo-institutional literature. Regarding the question how monitoring affects human behavior, one obvious way to think about institutions is in their physical manifestations. Policy-making and choice of designs deal, at times, with physical institutions, architectural structures, and monitoring to change behavior. Physical structure and appearance may be an important element in the effectiveness of a monitoring institution.

Architectural design can dictate a building's perceived function, or it can be a façade. The architecture of the Panopticon-utilized in some prisons - emphasizes how design can support function in the area of monitoring. According to Jacques-Alain Miller (1987), the ability of the watcher to "observe without being seen... is the most cunning thing about the Panopticon". Hidden from the prison's inmates, the surveyor is able to see throughout the circular structure. Prisoners feel the watcher's omnipresence, regardless of whether or not 
they are in fact being monitored. Jacques-Alain and Miller reinforce that the combination of "apparent omnipresence" and "real presence" intensifies the patrol effect. The Panopticon's architectural design conveys a point critical to questions of policy design: How to convey a constant presence of being surveyed - monitored - among individuals in situations where behavioral control is the goal.

Policy choices regarding institutional design of monitoring can take equally "strong-armed" forms in the world of everyday governance. The role of the Stasi in former East Germany and similar state police in other authoritarian contexts exemplify equally blunt but non-physical forms of top-down institutionalization of monitoring. The Stasi's omnipresent scope and effectiveness grew out of its repressive tactics and daunting brutality, both physically and emotionally (Bruce, 2010).

Monitoring obviously has other, more subtle, ways to change human behavior through policy design. Bateson, Nettle and Roberts (2006), for example, suggest that just the reminder that others might be watching and/or an appeal to one's conscience might be enough to change an individual's behavior. In their study, a photograph of a pair of eyes was placed above a beverage station where payment was based on an honesty system. Their study found that the photograph proved effect as an effective monitoring instrument in terms of whether or not users paid for the drinks they consumed. Contribution levels were 2.76 times greater when the photograph of eyes was posted above the beverage station than when a control image of flowers was shown. Apparently people are more likely to obey the rules even if an inanimate object suggests someone is watching. Similarly, armed law enforcement is typically less approachable than a handwritten note "Do Not Enter" sign. The latter is obviously less expensive but the question remains how effective it is in altering behavior.

The architectural example of the institutionalization or structuring of monitoring has the advantage of constant watching (or the feeling of constant watching) but it comes with very high financial costs. The low costs of a photograph of a pair of eyes to change behavior is clearly an advantage, but may come with a trade-off in terms of effectiveness. Designs that fall somewhat in-between these two quite varied design choices in terms of effectiveness and cost should clearly be part of the design choice menu. Policy oriented designs that both clearly work well and minimize costs are generally strongly preferred in the real-world of politics and governance.

Design choice in policy making that incorporates monitoring range from omnipresent watching to occasional observation to artificial watching. It can also vary widely between "strong-armed" designs to "softer" monitoring techniques in order to improve chances for obtaining more optimal collective outcomes.

The "Plimsoll line" is a good example of how creative and insightful policy design utilizing monitoring as a central component can be found to overcome collective action problems. Summarizing the details, during the 19th century firms in the English commercial shipping industry were facing a classic sub-optimal collective outcome. Economic incentives to maximize profits meant that firms tended to load as much cargo as physically possible onto each commercial ship; loading more onto each ship increased each ship's potential for adding to the firm's financial bottom line. Problem is that overloaded ships tend to sink more often given storms and other problems. Rationally motivated, the shipping firms began to insure their ships with some of England biggest and best known insurance companies. In due course, however, such contracting only served to shift the financial losses from the shipping industry to the insurance industry. The latter, often based in London, sought help from the British Parliament. Samuel Plimsoll, MP (1824-1898) from the harbor town of Bristol designed a very simple and effective solution. He envisioned the idea, and as a parliamentarian made sure it became part of British law, that all ships were required to have a horizontal line on their hulls that parallels the water. 
Regulation determined how high up the hull the line must be placed. The result was simple and readily transparent: No ship could load itself with more cargo than the weight of which pushed the line, through the physics of buoyancy, below the waterline. If they did, they were heavily fined and sanctioned in other ways. The collective action problem was immediately solved. Why? Plimsoll's solution, with minimal government intervention in the market, made transparency high and costs of enforcement low-ships passing any competitor on the sea can readily monitor if they are violating the rule and report them (without the need of government-hired monitors) to the authorities. To this day, one can find a bust of Samuel Plimsoll, MP on the Avon River near Bristol's harbor to honor his simple and insightful contribution to the English shipping. Anyone looking at a freighter today can readily see, from the line formed on every ship from two distinct colors of the hull that this solution has been copied worldwide. The monitoring mechanism - the Plimsoll line-is now part of international law

\section{Theory to Guide Policy Making}

Such examples of variations in policy-making design and its effects push one to raise fundamental questions about the role of state regulation in policy making. If one assumes that, among other things, policy-making plays a critical role in the production of "good governance", one must also address the critical question "When should public authority seek to change behavior and when should it be left to non-public entities or even to individuals themselves?" Assuming that rule determination and institution-building are critical infra-structure for the achievement of good governance, then when is good governance best or most effectively handled by public authorities and when should it be outside the realm of the state?

As a step in addressing this fundamental question when considering the role of monitoring in seeking to produce good governance, policy-makers and analysts might take into consideration two essential aspects of types of design. Both contain theoretical as well as practical sets of issues for policymakers, and both are well grounded in the scholarly literature. The first of these asks if the monitoring should be of a "policing or fire alarms" design. The second questions what behavior should be criminalized by authorities and what actions are best regulated by social norms. Answers to both these lines of inquiry have important implications for the design of monitoring.

The first policy dimension assumes monitoring exists and that it might take one of two forms. McCubbins and Schwartz (1984) compare these as "police-patrol" and "fire-alarm" oversight. Police-patrol oversight is centralized, active, and direct. It involves hands-on monitoring analogous to using real police patrols in the streets and elsewhere. Fire-alarm oversight, moreover, involves a more passive system than has mechanisms in place to alert the monitor when a certain activity occurs or an event is happening. Similar to fire-alarms in that it alerts people when there is a "fire", the police-patrol technique differs in that it does not require constant action and effort.

A key question in policy-making and policy design choices is which of these two types of monitoring should be utilized in any given situation. Both have advantages and disadvantages. For example, in terms of costs, fire-alarm techniques may require more start-up costs through infrastructure investments while police-patrols may entail more over-time and on-going expenses such as higher labor costs. What's more, police-patrol monitoring has a more face-to-face and human touch to it, which likely affects other important contextual variables such as trust (Lancaster, 2014, p. 257; Ostrom \& Walker, 2003). The effectiveness of a particular monitoring design and technique will also affect policy-makers choice. While questions of 
measurement, data gathering, and normative issues such as privacy rights unquestionably enter the decision-making, whether or not a technique or design "works" will certainly be part of the conversation.

A second dimension to policy making involving monitoring asks if the state contains the appropriate set of structures within which to institutionalize monitoring to achieve good governance. The flip side of the same question, of course, asks if societal and private actors - and not the state - are utilized in any necessary monitoring functions needed to achieve good governance? One way to address this - in the context of an institutional analysis - is to ask when should a type of behavior or practice be outlawed that is detrimental to the collective good? When should the state legally forbid a behavior - and have the state put its weight behind attempts to enforce prohibition? When should the state not forbid something because "softer" and "less formal" societal rules and institutions effectively regulate the behavior?

Legal studies shed interesting light on this dimension. Importantly, one should recognize that the question of criminalization is of a highly political nature (Haenen, 2014, p. 119). With that understood, "certain guidelines can be distilled from legal doctrine" (Haenen, 2014, p. 119). Developing criteria for the criminalization of behavior from theories normally applied in the context of national legal systems, Haenen emphasizes a dual-element threshold for the criminalization of behavior: wrongfulness (based on legal moralism) and harmfulness (Haenen, 2014, pp. 122-123).

In terms of collective action theory, harm is the most important analytically. J. S. Mill (1859), the auctor intellectualis of the need to limit harm, argues in On Liberty that "the only purpose for which power can be rightfully exercised over any member of a civilized community, against his will, is to prevent harm to others" (p. 22). He thus argues the state can legitimately impose a negative constraint on "harmful" behavior (p. 123). While much in legal theory focuses on harm to individuals, generally in a personal (often physical) or proprietary sense, harm to society is also relevant here. As Haenen (2014) stated, "Harm without an obvious victim can also amount to criminal harm. Good examples are evading taxes and polluting the environment, two acts which cause harm to society. Then there is an entire category of behavior that has been criminalized because it causes risk of harm, such as gun possession and driving while under the influence" (p. 124). Such "harm to society" is often analytically captured in the study of collective action problems - which is where questions of the role and institutionalization of monitoring arise.

Central to Kaenen's legal analysis is that "Conduct that is harmful can be criminalized, but the harm principle does not imply that such conduct must be criminalized" (p. 125) is important to policy designers. A key analytical point to apply in public design in general and specifically to questions about policy decisions regarding monitoring is that variation exits along a social norms-criminalization dimension. Ultimately, policy makers must place any policy design at some specific point along this dimension that captures variation between letting society do the monitoring (a sort of bottom-up monitoring) or having the state perform this function (a more top-down approach to monitoring) through some short of "hard" structures or rules, possibly of a legal nature.

These two dimensions - police-patrol versus "fire-alarm" monitoring and the criminalization of behavior verses leaving it in the realm of social norms - suggest that both, in a combined manner, are needed to help decision-makers understand the policy and design questions faced in addressing specific issues important to good governance. With an interest in generalization and heuristically organizing such discussions Figure 1 places these two dimensions orthogonally to each other. 


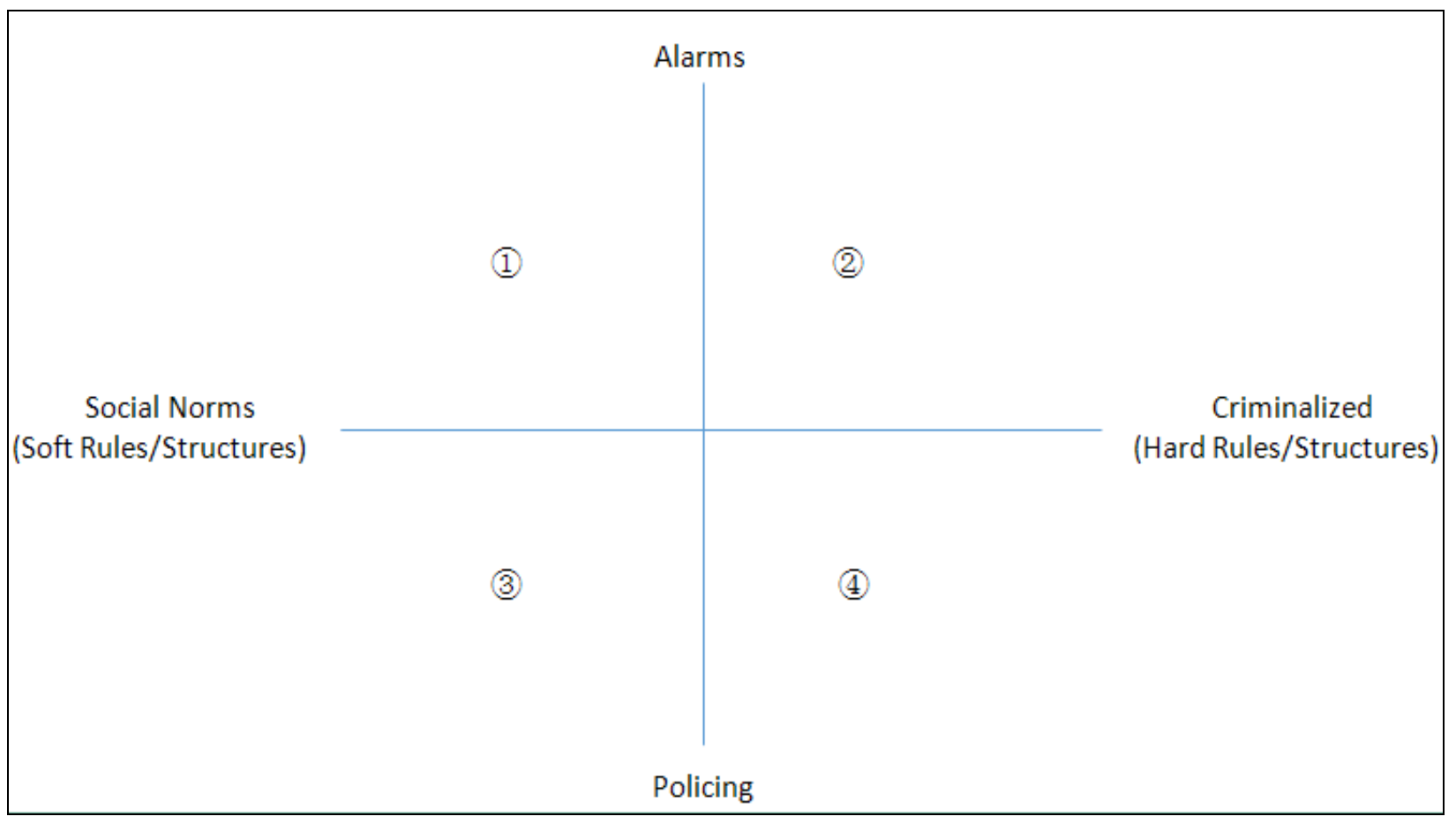

Figure 1. Two-Dimensional policy choices in monitoring designs of behavior.

Importantly analytically is that most design questions involving monitoring mechanism that arise in response to specific collective action issues will fit well within one of these four analytical quadrants. Take for example the cases, discussed above, of the eyes at the beverage station, the Plimsoll line, and the Panopticon and the Stasi. The logic of design of the eyes at the beverage station is that it relies upon social norms in its quest to induce a behavioral change, placing it either in Quadrant 1 or 3. The constant watching of the eyes suggest a certain policing element but the goal, of course, is a self-monitoring set in which the hope is the setting off of an internal, psychological, alarm in the individual's own moral compass. The Plimsoll line example of mutual monitoring by shippers appears to characterize Quadrant 2. The effectiveness of the policy design required a limited intervention by the British Parliament while the bulk of the monitoring of the behavior of individual ships is done by competing shippers. And, the Panopticon as well as state secret police such as the Stasi clearly fall with Quadrant 4's classification where state-enforced criminalization exists as well as constant, top-down monitoring.

With Figure 1's heuristic model in mind, the analysis now turns to three equally diverse examples of institutionalizing through design monitoring in order to affect behavior outcomes. These three illustrative examples were chosen to demonstrate such variety in design as well as to provide empirical evidence that political monitoring does in fact affect behavioral outcomes. The first - an example of policy design involving surveillance systems for police work - shows a case shifting from Figure 1's Quadrant 2 to Quadrant 4. The second-about government corruption and the press - is an example of movement between Quadrant 2 and Quadrant 1. The third looks at the impact of environmental management certification in the industrializing world to reflect analytically movement from Quadrant 1 to Quadrant 3. Each of the three empirical illustrations highlight the analytical value-added of Figure 1 in theorizing about the component parts of how to best design mechanisms of political monitoring to achieve desirable behavioral outcomes. 


\section{Illustrative Examples with Empirical Evidence}

\section{Top-Down Political Monitoring: Surveillance Systems}

The city of East Orange, New Jersey has long been considered one of the most dangerous cities in the United States, including being labeled as one of its "murder capitals". Neighboring New York City and within 30 miles of Manhattan, uncontrollable crime dominated this community in the 1990s and early 2000s. Before 2006, East Orange had a crime rate that was twice the national average and had an average of five cars stolen daily (NJ.com, 2014). By 2006, all crime was down - the murder rate fell by almost two-thirds and robberies by one-half (NJ.com, 2014). Why the change in criminal behavior? With implementation beginning in 2003, the East Orange police department changed its policing strategy, investing millions of dollars in new technology. Two changes appear especially significant. First, city authorities installed surveillance cameras throughout the city that allowed the police force to monitor city streets from a control room filled with computer screens. Second, they also instituted the use of microphones throughout the city to detect and locate gunshots, taking advantage of Shot Spotter technology.

Figures 2-4 present longitudinal data on violent crime, all crime, and the number of murders in East Orange, New Jersey from 1985 to 2014. The solid black vertical line indicates when, in the latter part of 2002, the city's new "policing monitoring" policy was instituted. Within a few years, the crime rate clearly and significantly dropped. Such an interrupted time-series strongly suggests that criminals change their behavior when they are being watched! While more refined research undoubtedly needs to substantiate this conclusion in greater detail, Figures 5-6 reject possible counter-arguments-such as change in overall population or a lowering of the unemployment rate, which often co-varies with crime rates-are not especially convincing. Moreover, and reported here, comparable changes in criminal behavior following similar monitoring-oriented policy changes appear to have occurred in other cities such as Camden, New Jersey, outside of Philadelphia, when that city completed its implementation of a similar program in 2012 (Nytimes.com, 2012).

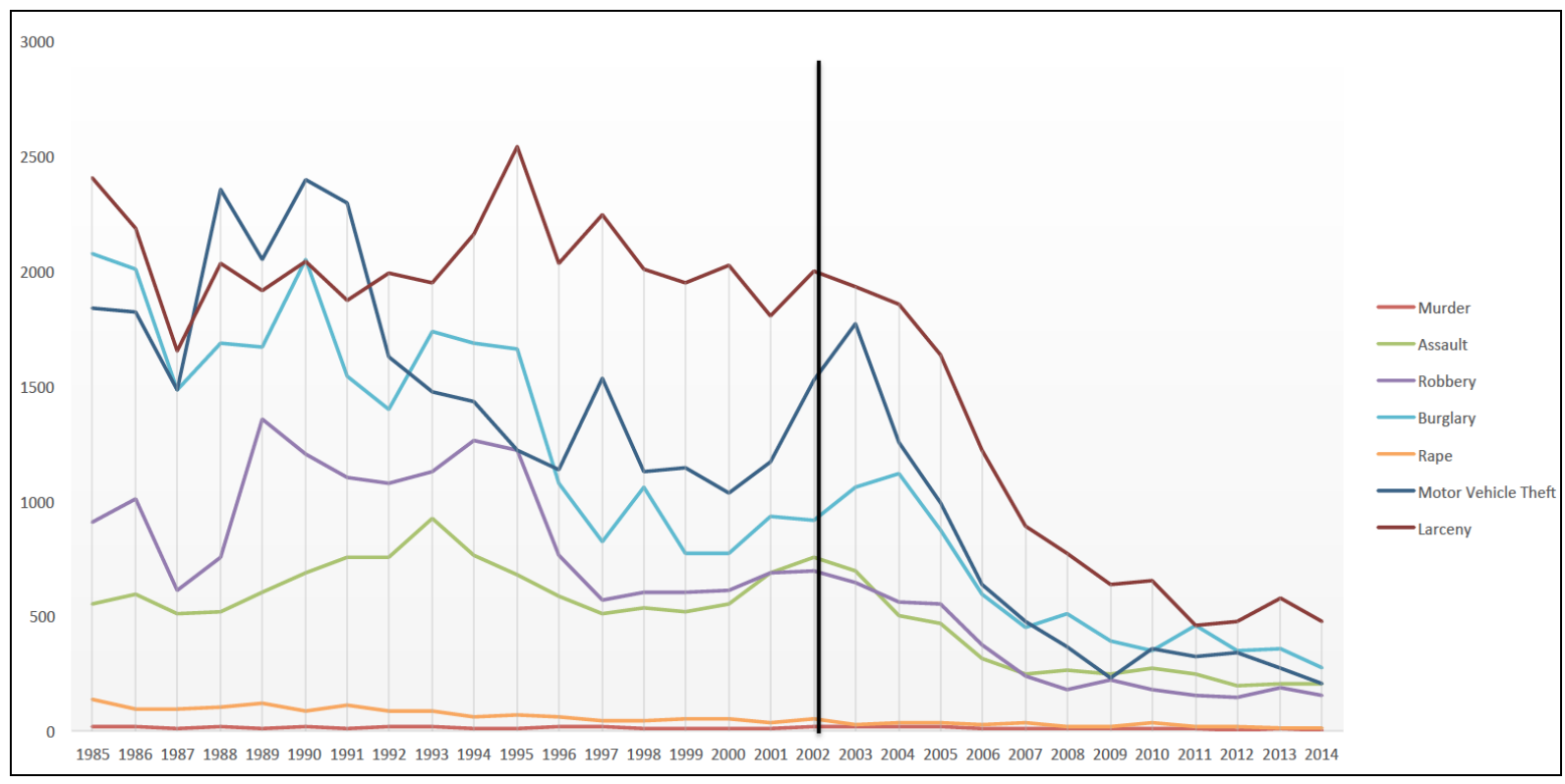

Figure 2. East Orange, NJ All Crime, 1985-2014. 
Two points might be emphasized here - one theoretical and one more policy oriented. First, regarding Figure 1's theoretical framework, this example of policy choice about the use of surveillance systems is all about decreasing the amount of criminal activity, not about changing the legal standing of the behavior. In terms of design, however, the implementation of the surveillance systems did reflect a shift along Figure 1's alarms-policing dimension, thus shifting the classification of this case from Quadrant 2 to Quadrant 4.

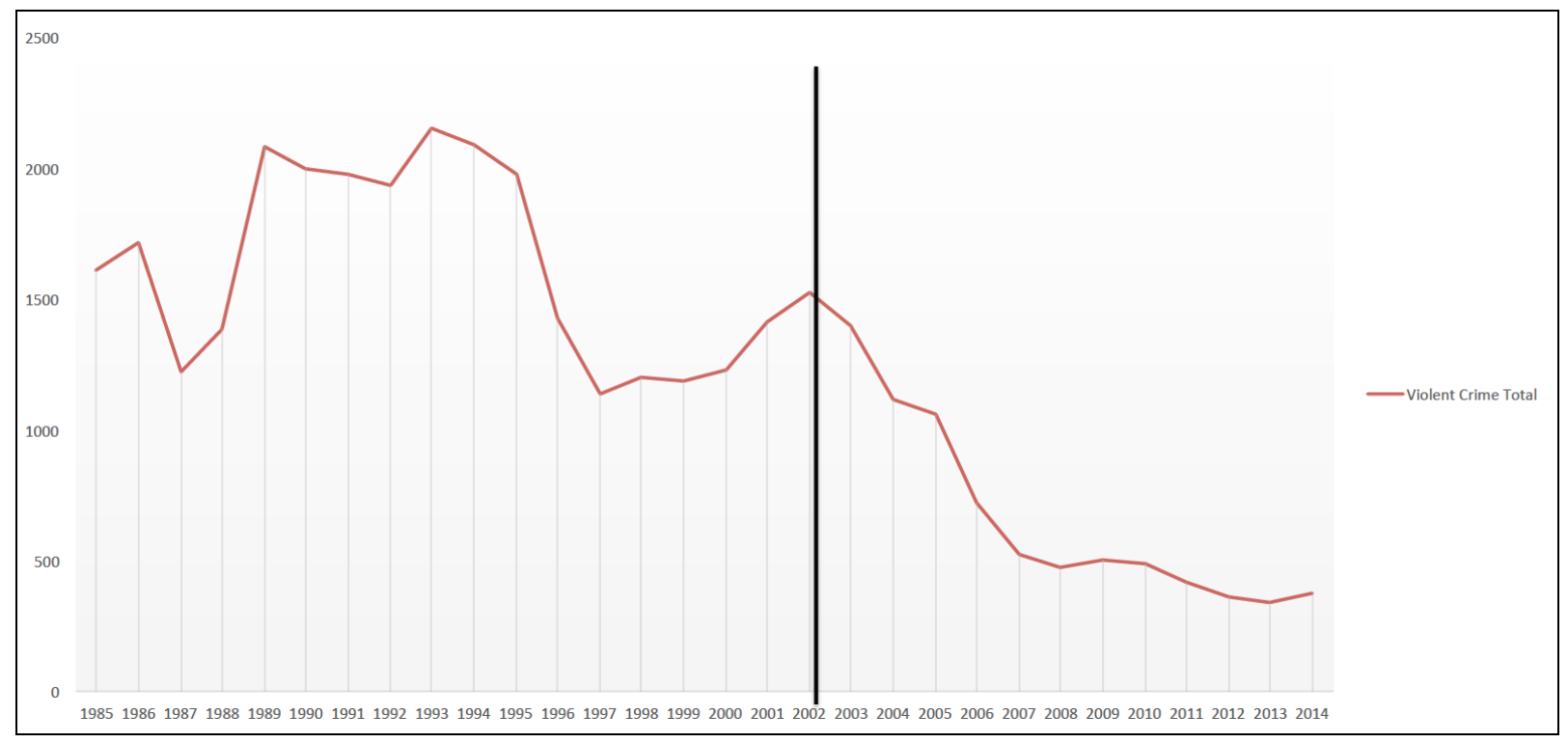

Figure 3. East Orange, NJ Violent Crime Total, 1985-2014.

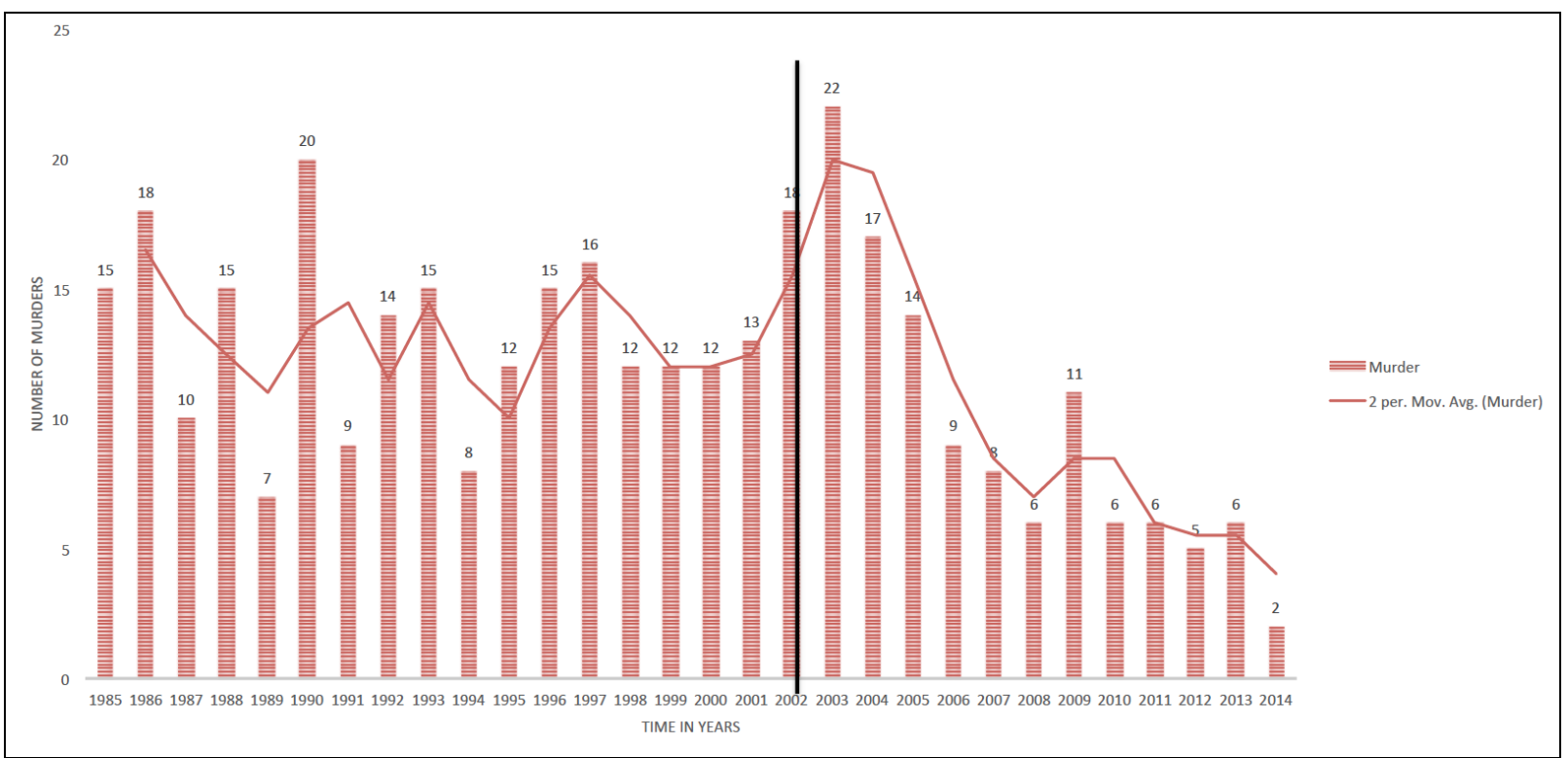

Figure 4. East Orange, NJ Murders, 1985-2014.

In terms of policy orientation and design, costs are a necessary consideration in the politics of monitoring (Lancaster, 2014, p. 262; Table 3; Ostrom, 1990). Police departments and policy-makers undoubtedly conduct some form of cost-benefit analysis regarding the methods they use for crime prevention and law enforcement (Of course, the criminals are also balancing the benefits and potential costs/risks/sanctions related to the 
commitment of a crime). Formally or informally, they generally weigh the costs and payoffs of each policy choice in trying to find the cheapest and most efficient solution. The politics of monitoring is significant here because the costs of installing cameras and other high-tech surveillance systems is likely cheaper-especially given the trend of price decreases in providing such technology — than personnel costs including hiring, training, equipping, and paying for more police officers. Such monitoring, with its obvious policy choices and implications, is a viable option when decision-makers consider law enforcement and crime prevention. The most significant question is not just if it is possible but what are the implications of such policy design.

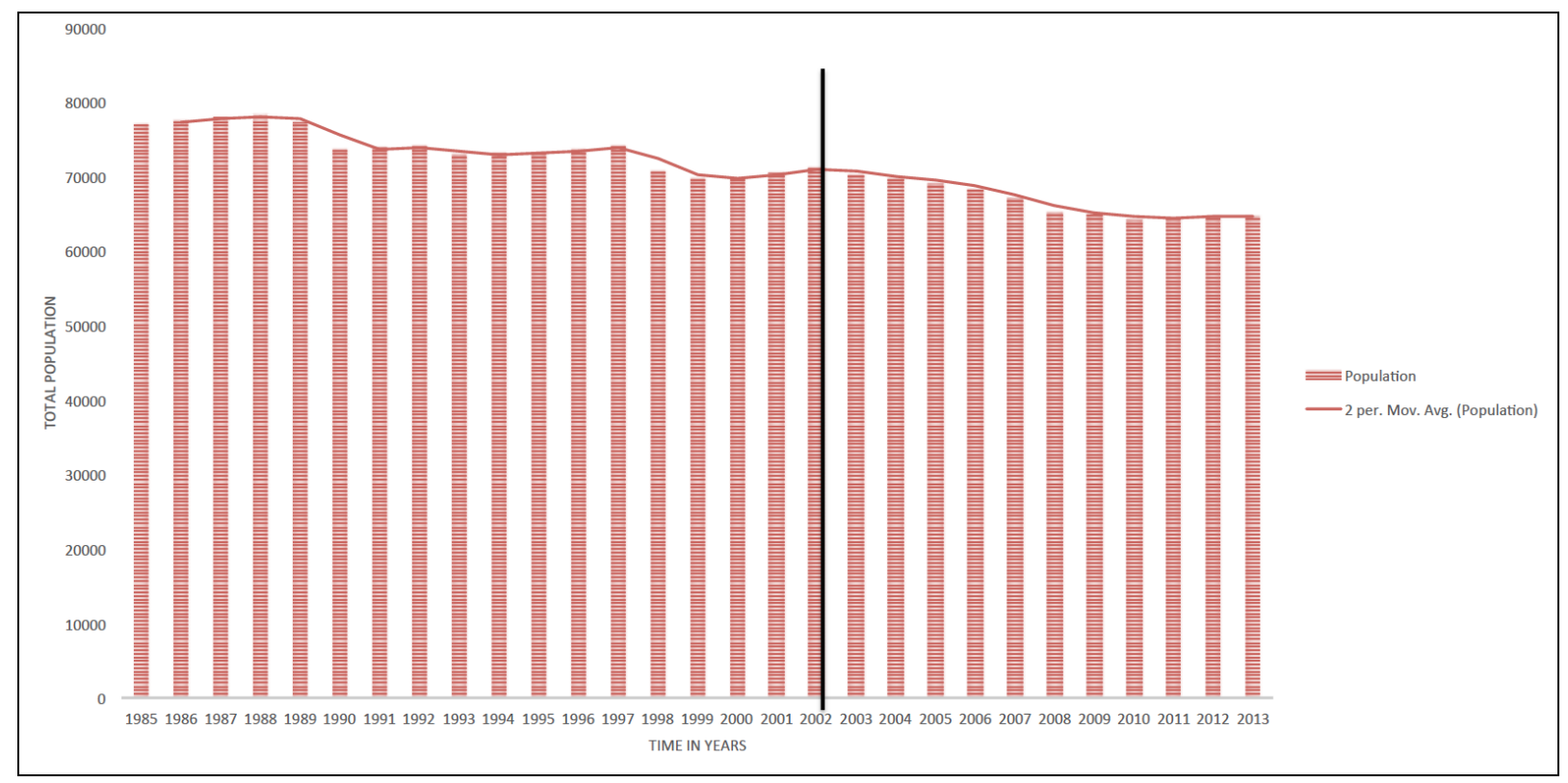

Figure 5. East Orange, NJ Population, 1985-2013.

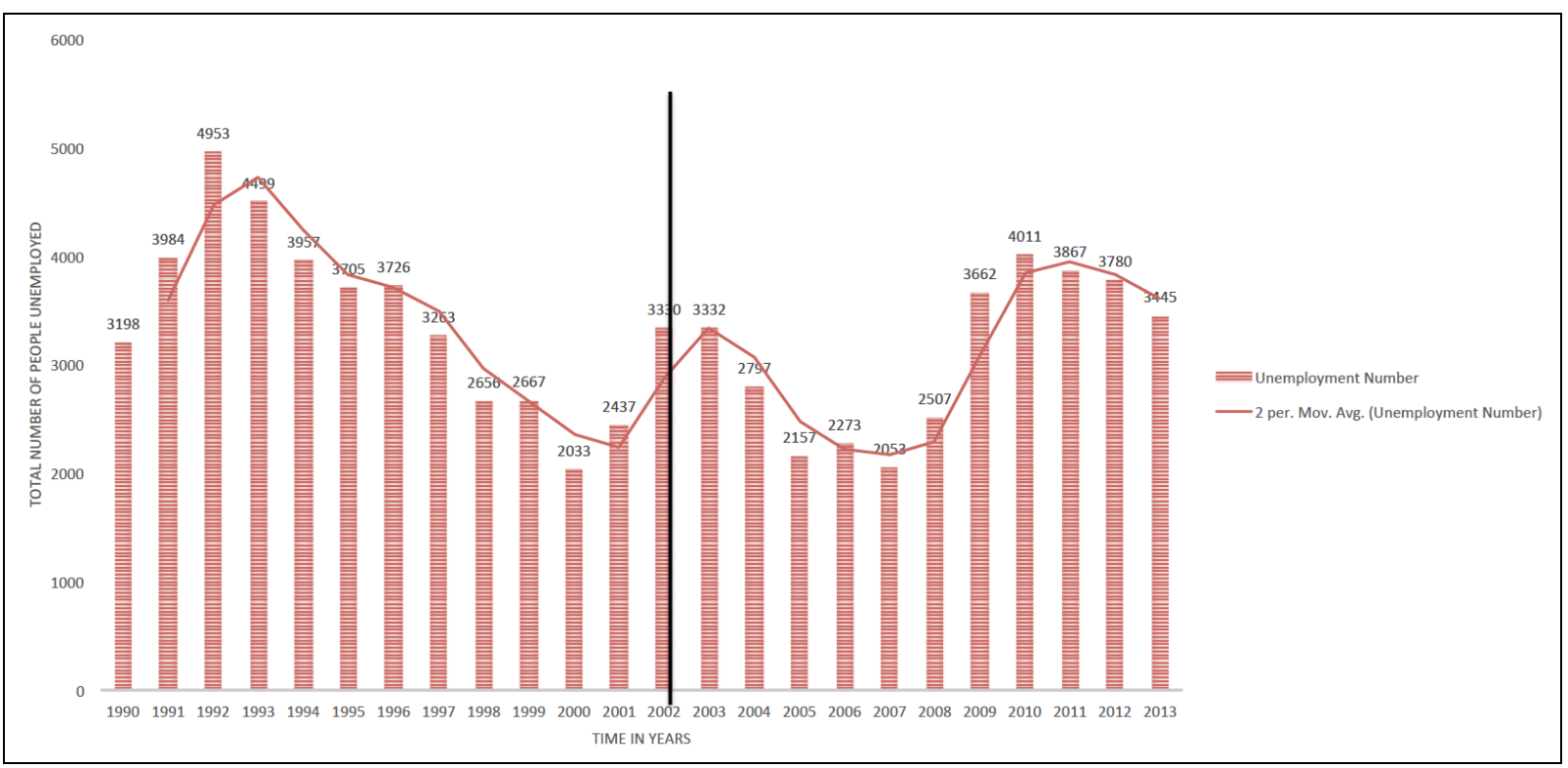

Figure 6. East Orange, NJ Unemployment, 1990-2013. 


\section{Bottom-Up Political Monitoring: Corruption and the Press}

The study of political corruption has grown asymptotically over the past several decades, and for good reasons. Initially dominated by case study analysis, more broad-based comparative and theoretical explanations have now added to our understanding of why political corruption develops and persists in some countries but not in others. Policy-oriented and other scholars recognize, both normatively and empirically, that the major problem with political corruption is it threatens trust in public authority-a question of political legitimacy - and generally and significantly is associated with negative economic consequences, including development (Chowdhury, 2004; Freille, et. al., 2007). Amongst many other influences on the emergence and persistence of political corruption, the role of a free press as a watchdog of government activity is often lauded as a means for minimizing, or at least lessening through exposure, corrupt activities by public authorities (Brunetti \& Weder, 2003). A lack of press freedom may hurt the efforts of watchdog journalists and reduce their effectiveness in monitoring the state (Besley \& Prat, 2006). Simply stated, the media, in all its forms, potentially serves as effective watchdog against political corruption by monitoring state actors. It does so by increasing its reach among society and adds transparency by closing the information gap between the state and the people. A freer press can provide greater information to citizens so, in democracies, they can vote for a candidate or party that is not siphoning of public resources for its own gain. This, of course, is the class example of the principle-agent problem, where citizens are the principles, the state is the agent, and the media impacts this relationship by addressing the issue of asymmetric information.

While cases are all too readily found throughout the world, one empirical example of the potentially positive relationship, in a normative sense, in the tension between an opposition press and actors engaged in corrupt activities can be found in Latin America during the early part of the 21st century. Methodologically, the regional focus on Latin American democracies permits controls, through a most similar systems research design, of many explanatory factors of a regional nature such as a common history and culture, stemming from similar patterns of colonization, diversity of ethnic composition, transition from dictatorship to democracy, etc. Moreover, all of the countries included in this study are considered democracies as verified by the Carter Center (2014), which has sent election monitoring teams to various countries in the region (although Cuba was left out given its authoritarian tendencies and Honduras, Nicaragua, and the Dominican Republic were excluded due to difficulties in obtaining early data). Substantively, this period was characterized by conflict between many governments in Latin America and an opposition press, with the governments coming under attack by the private media for not favoring business-friendly measures and the press seeking policies of social inclusion that benefitted the large population of marginalized poor in the region. The surge during elections of left-leaning politicians came to be known as the "Pink Tide". They favored courting foreign investment and thus the reference to pink rather than red (BBC News, 2005).

Figure 7 reports a rather straightforward scatter plot of the two most important variables related to this question. The vertical axis plots Latin American countries on Transparency International's scores for each country on TI's 2014 Corruption Perceptions Index (TI's scores of 0 (highly corrupt) to 100 (very clean) have been reversed to facilitate interpretation). Fully acknowledging the many different problems in operationalizing and measuring "corruption" and the TI index itself which focuses on the perception of business people (Lancaster \& Montinola, 1997, 2001), such a standard and widely used measure facilitates the central point to be made by this paper's illustrative example of policy design, monitoring, and behavior (Transparency 
International, 2014).

In terms of monitoring as an explanation of level of corruption, Figure 7's horizontal axis reports data that assume that greater press freedom should allow journalists more room to investigate the state activities more freely and thus to dis-incentivize corrupt behavior. Press Freedom as a measure seeks to operationalize the notion that journalists serve as monitors of state behavior. Press freedom is measured here through the use of the Press Freedom Index from Transparency International (2014), which is based on research done by Reporters Without Borders which sends out questionnaires to partner organizations in order to determine such things as the presence of media organizations, harassment, physical attacks, threats, and other measures. As with the TI's measure of corruption, the Press Freedom Index report in Figure 7 has been reversed for ease of interpretation, so that no press freedom equals 0 and that 100 is the highest of press freedom.

Despite possible questions about causal direction-including plausible arguments that corruption itself may be directed at the media, thus creating a disincentive for the press to fill faithfully its watchdog role- $\mathrm{a}$ logical argument suggests that press freedom facilitates monitoring and thus affects levels of corruption. Figure 7 suggests that in 2014 press freedom tends to be negatively related with corruption: The greater the press freedom in a Latin American country the lower the level of corruption tends to be. Such a general pattern suggests that macro-level design decisions about the amount of room the press is given to monitor public officials and business people impacts corruption as a specific type of behavior.

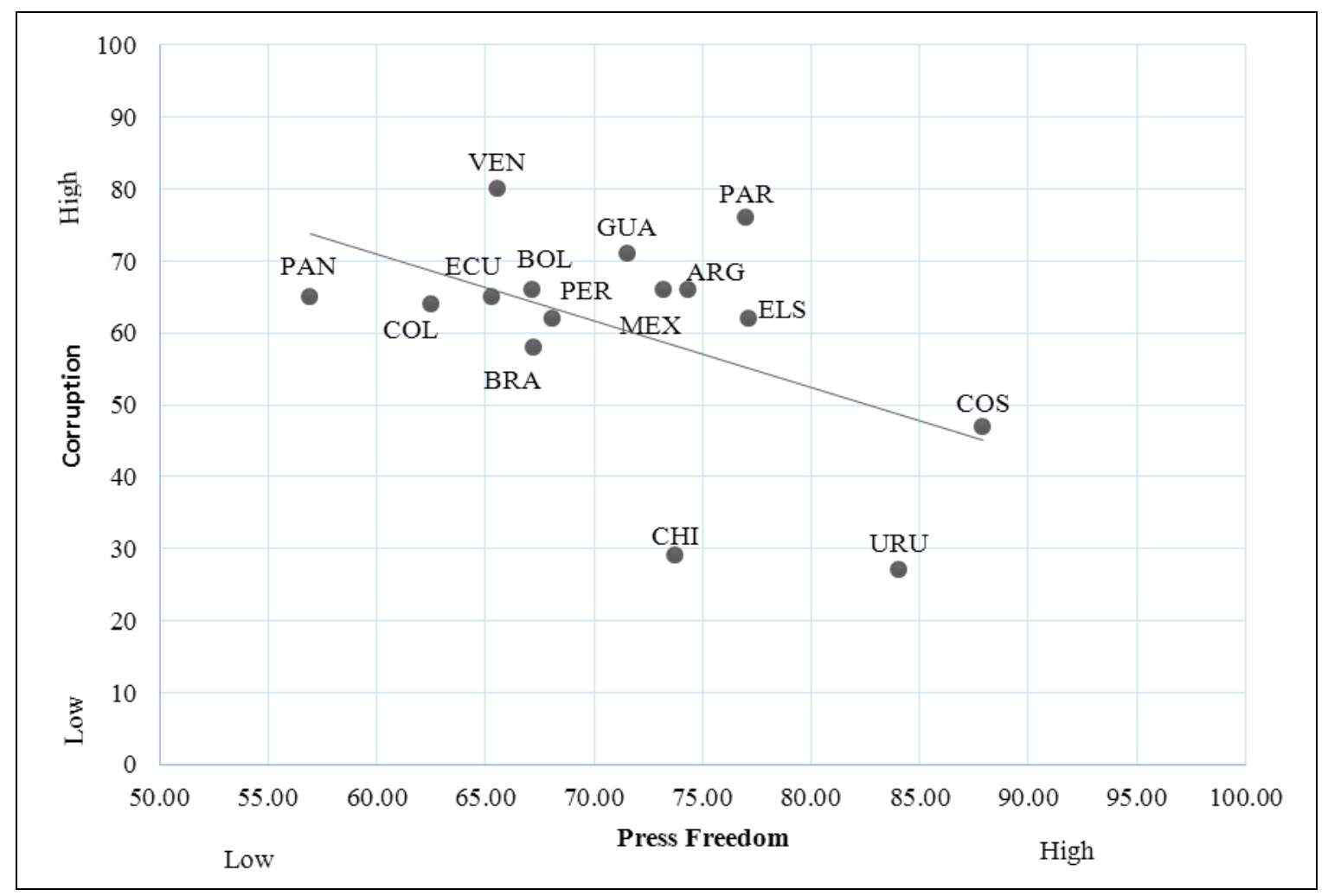

Figure 7. Corruption by Press Freedom in Latin America, 2014.

Figure 8 contains the same type of data for the same Latin American countries, only this time in 2002. The relationship between the potential for press monitoring and corruption as an outcome in this earlier period was also a negative one. Contrasting Figure 7 and Figure 8, however, suggests that this relationship has changed 
over time - that it has strengthened in a negative direction - a direction most observers normatively find preferable. This hints that corruption may potentially be altered when considered thought is given to policy design at the marco-level, in this case in terms of how to best insure press freedom.

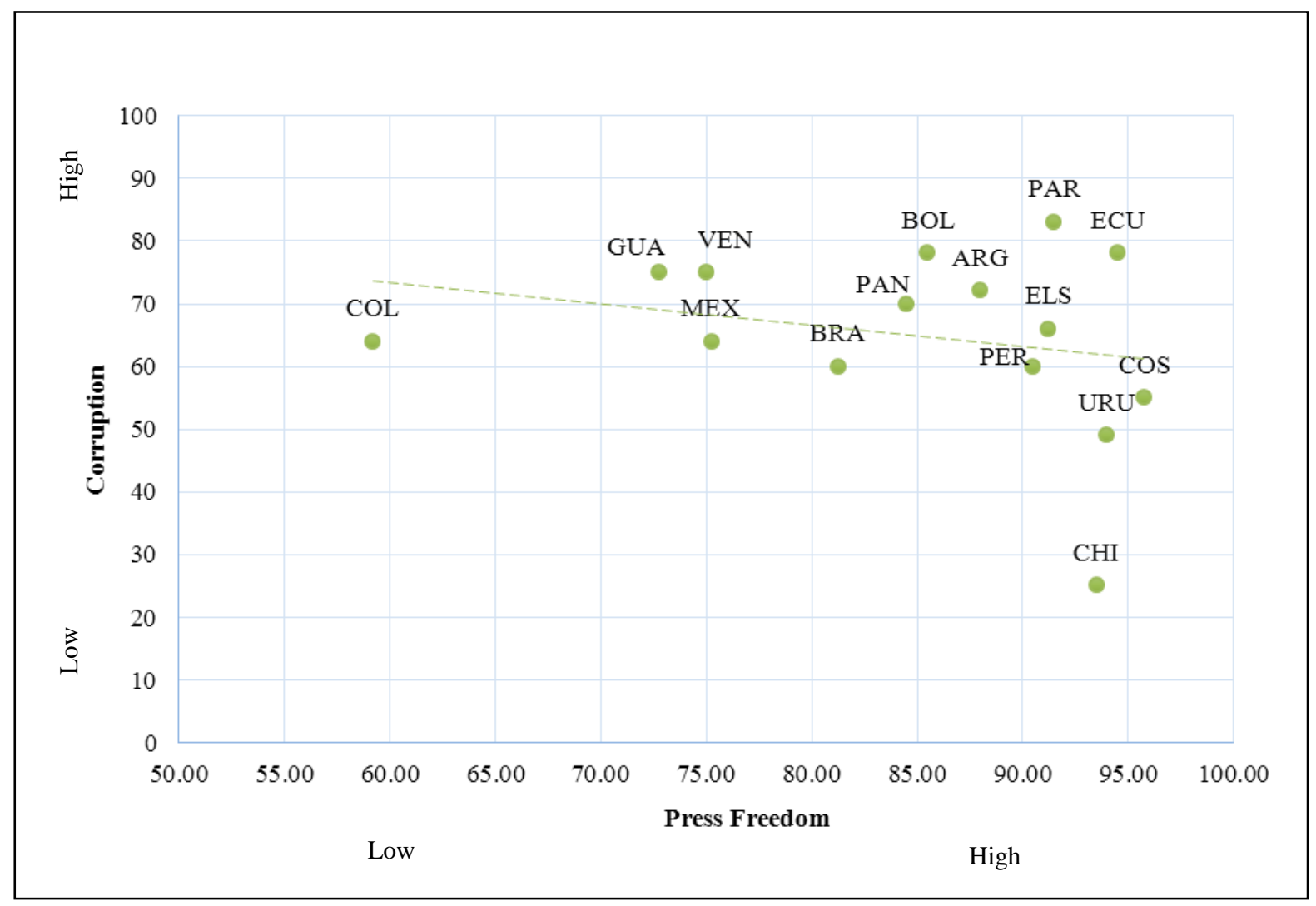

Figure 8. Corruption by Press Freedom in Latin America, 2002.

Such studies of how freedom of the press impacts its ability to hold the government accountable demonstrates well the press's vital monitoring role in advancing the values of liberal democracies. Key, of course, is that it serves a vital "alarm role" and, in making information available to the general public about government activities is trying to expose criminal activity so that the public will react at the ballot box (which, in fact, they may choose not to do so). Such a process suggests a movement in Figure 1's theoretical schema from Quadrant 2 to Quadrant 1.

\section{Micro-Level Political Monitoring: Environmental Management Certification}

Questions about design and non-design in policy-making are fundamentally important in a world increasingly concerned about the environment and how we can best manage and protect our planet. Environmental Management Systems (EMS) vary in structure and requirements. In terms of similarities, however, they are all voluntary and include a formal monitoring component to measure progress and ensure that the program's goals are being met. The ISO 14001 standard, developed by the International Organization for Standardization in 1996 is, by far, the most ubiquitous EMS. This framework is the "official international standard" (US Environmental Protection Agency, April 2013). ISO 14001 is a certification-based program where a firm meets with a team of ISO officials to develop specific environmental goals to complete by an 
outlined time. To ensure that the firm adheres to its commitments, the ISO framework includes regular monitoring, both within the company and by a certified external auditing body. While relatively new, ISO 14001 is increasingly more far-reaching across industries, economics, and cultures. The ISP program as a whole, but the external auditing piece in particular, appears primarily responsible for the private sector's increasing determination to develop more environmentally sound business practices. The hope held by many in the environmental policy-making world is that this standard will continue to incentivize changes in individual company's business culture - and without having to resort to government oversight to accomplish this.

Consistent with Ostrom's theorizing and preferences about monitoring in Governing the Commons (1990), ISO 14001 provides an opportunity to institutionalize corporate environmental monitoring in the absence of government oversight. ISO 14001 utilizes local management in that the directly-involved appropriators take part in the development of institutions, yet manages to incorporate these principles on a global scale. Firms are thus able to take part in the crafting of their own goals and, consequently, appear more willing to take up additional regulations. It also means, and again consistent with Ostrom's argument, that the entire system hinges upon the willingness of firms to adopt the standard and open up the firm to voluntary regulations as well as regular system audits. One might expect that firms, and especially those in emerging economies, might be reluctant to adopt and maintain ISO 14001 certification requirements. Neumayer and Perkins (2004), however, state that in the years preceding their study, there had been a large uptake in certifications for firms in emerging economies. With an interest in the uneven geographic distribution of ISO 14001 certifications, they analyze data that indicate that "variations in the take-up of ISO 14001 can be explained by differences in the incentive structures facing the firms" and that "firms are more likely to adopt ISO 14001 where they face strong incentives to do so" (Neumayer \& Perkins, 2004, p. 835).

What monitoring-related incentive structure helps explain at least part of this increase in ISO 14001's voluntary commitments and complain to its requirement? The following argument suggests that ISO certification acts as a show of commitment to potential foreign investors who might hold preferences regarding environmental management-rather than indicating a nation's own preferences about such environmental issues.

Two theoretical components are crucial. First, frameworks about principal-agent relationships are particularly applicable to the EMS structure. In the principal-agent relationship, a principal actor hires or delegates a task to another actor, often due to a lack of time to personally oversee the task or due to a lack of knowledge as to how to carry it out. The agent then serves as a proxy for the principal, making decisions on the principal's behalf. These problem, of course, is that it is very difficult to ascertain whether the agent's incentives are in line with the principal's. When foreign companies or private entities choose to invest in a firm from a developing economy, the foreign company can be thought of as the principal. Preferences may be aligned between the two at the time of investment, and such investments may be very profitable in the short-run, but differences in objectives over time may create an unfavorable situation for the principal. If a foreign investor cares deeply about environmental issues, one might expect the firms invest in countries sharing the investors' values and commitments. Alternatively, an investor who has moved to a stronger commitment to sustainability - particularly when urged by the public or stock holders — will not want to associate with a firm that is still carrying out unsound management practices. ISO 14001 provides a means for the principle to ensure that the agent is committed to the same environmental ethics. The foreign investor can confidently move forward without vigilantly watching its agent-because someone else is doing the monitoring. 
Second, transparency and trust as necessary components of effective monitoring (Lancaster, 2014, p. 257). A foreign investor's ability to monitor potential businesses of interest is enhanced with international certification standards such as ISO 14001. Regarding environmental management practices, investors need only look for a firm's ISO 14001 certification, as well as the length of time it has been in place and whether certification was lost at any point, to determine if the firm shares the same standards and principles. Firms know this. By voluntarily subjecting itself to increased monitoring, the firm demonstrates it shares the investors' standards and concerns. In this manner, monitoring acts as a mechanism that incentives a firm to synchronize its practices with those of those investing in it. Such a monitoring-centered system design differs widely from any type of blanket government-based regulatory system.

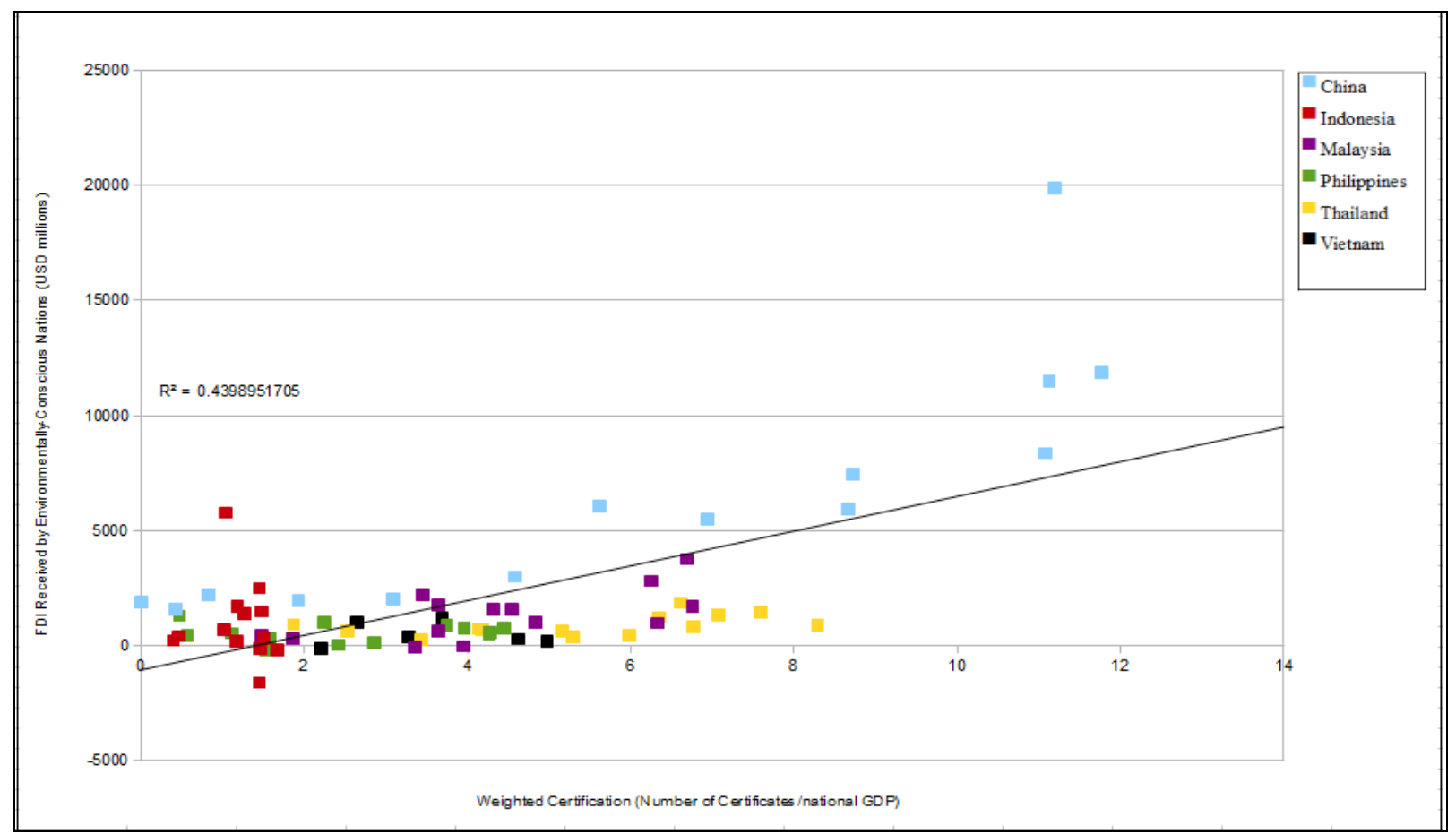

Figure 9. FDI by ISO 14001 in emerging Asian economies.

A great deal of debate exists regarding the effectiveness of ISO 14001 certification. My argument is that ISO 14001 serves as a monitoring mechanism that increases transparency and trust for investors interested in developing-world firms: a low cost, trustworthy, and transparent monitoring effort adding to the perception of a firm's environmentally-conscious orientation should attract investors from countries who share similar convictions. Figure 9 empirically suggests this pattern does in fact exist. In terms of case selection, for investing nations the Environmental Performance Index (EPI)'s country rankings were consulted given its ranking of countries according to a number of factors including environmental health, ecosystem vitality, emissions per capita, etc. (EPI, January 2014). Switzerland, Germany, Denmark, the Netherlands, the United Kingdom, and Sweden were included in this study given the larger size of their economies (as compared to Luxembourg which was ranked second on the EPI list in 2014), their tendency to invest in foreign businesses, and the assumption that they have histories of being environmentally oriented. For emerging, industrial economies, Figure 9 reports data from countries in South Asia and the Pacific (to hold constant for other factors) designated by the International Monetary Fund as "emerging economies": China, Indonesia, Malaysia, the 
Philippines, Thailand, and Vietnam (IMF World Economic Outlook, 2012). The logic of this selection, at face value, appears appropriate, given that the region as a whole has seen one of the largest uptakes in ISO 14001 certifications yet a great deal of country variation exists and not all has been in a positive direction.

As an indicator of direct foreign investment from the group of environmentally-conscious countries, OECD data on outward FDI flows (in USD millions) being invested in the specific South Asian and Pacific partners were obtained for the period from 1999 (the first year of ISO 14001 certification) and 2012 (the most recent data) (OECD Stat Extracts, January, 2013). Yearly FDI flows from the six European investing nations were then added for each of the South Asian and Pacific emerging countries.

The ISO reports annually the total number of ISO 14001 certifications granted to firms in each country (ISO Survey 2013). These data were then standardized by dividing that national GDP in the appropriate year (World Bank, January 2014).

While some across-country variation exists, overall Figure 9 indicates a relatively clear pattern in the relationship between foreign direct investment in developing countries and level of ISO 140001 certification. This initial finding supports the hypothesis that ISO 14001 as a monitoring-facilitating mechanism is positively associated with foreign direct investment from environmentally-conscious developed countries. The ISO 14001 program also illustrates how policy design can both institutionalize monitoring for international consumption which, in turn, has a significant impact on investment behavior in many countries' political economy. The ISO's institution building clearly enhances monitoring that operates in the area of Quadrant 1 and 3 in Figure 1 's theoretical schema. More specifically, the institutionalization of monitoring via the ISO 14001 mechanism shifted such process from Quadrant 1 to Quadrant 3.

\section{Conclusion}

As part of a much broader and on-going research project, this paper emphasized the importance of political monitoring as an analytical concept and related it to the study of institutional design. It emphasized that the concept of that political monitoring builds upon the psychological notion that people change their behavior if someone is watching them, or they believe someone is watching. The fact that the institutionalization of monitoring emphasizes the very political nature of the concept, the essay analytically connected questions about policy design with the description of three creative variants of how monitoring has been institutionalized: a "hard institutional" design such as the architectural features of the Panopticon, where someone may always be watching, literally from the "top-down"; a "softer institutional" design in terms of the Plimsoll line on sea-faring freighters, where "mutual monitoring" assists in overcoming sub-optimal collective outcomes; and a psychologically-induced "self-monitoring" mechanism in the form of a photograph of a pair of eyes at an honor-system run beverage station. Seeking greater generalization, the paper then took a more theoretical tone and presented a two-dimensional classification schema to enhance policy design analysis vis-à-vis political monitoring and to suggest how policy design might incorporate political monitoring in our quest for good governance (i.e., the effective development of principal agent relationship and the related overcoming of collective action problems). Finally, the paper presented three illustrative cases to demonstrate empirically that the institutionalization of political monitoring in fact does affect behavioral outcomes. The wide-ranging cases of policy design change in police surveillance systems in East Orange, New Jersey, the relationship of press freedom and corruption in Latin America, and the impact of an environmental management certification scheme in South Asia and the Pacific on the six European countries' investment 
behavior all suggest empirically that how we design monitoring mechanisms does affect behavioral outcomes in a variety of contexts and policy areas.

Three areas for future research readily stand out. First, this paper has sought to emphasize that the policy design literature should increasingly include the concept of political monitoring. Second, the cases described here have hopefully sensitized others to the fact that a myriad of cases exist in which political monitoring as a concept sheds light on not just policy design but also policy outcomes. While the details are also quite interesting, this paper has also suggested there are ways to generalize about such cases while remaining focused on the relationship between political monitoring and behavioral outcomes. Hopefully, Figure 1 analytically assists in how we can think about the component parts of how to best design mechanisms of political monitoring. Third, and most importantly, future research should continue to pursue the study of political monitoring - and its related issues such as costs, transparency, and trust - as simply one part of a larger sequence of good governance (Ostrom, 1990, p. 52; Lancaster, 2014, p. 255). Design and non-design questions are plentiful throughout movement in this sequence from constitutional choice, collective choice, and operational choice. Monitoring as a process is only one of several processes that fall within operational choice along with appropriation, provision, and enforcement.

\section{References}

Agrawal, A., \& Ostrom, E. (2006). Political science and conservation biology: A dialog of the deaf. Conservation Biology, 20(3), 681-682.

Bateson, M., Nettle, D., \& Roberts., G. (2006). Cues of being watched enhance cooperation in a real-world setting. Biology Letters, 2(3), 412-414.

BBC News. (March 2, 2005). South America's leftward sweep. Retrieved December 10, 2014, from http://news.bbc.co.uk/2/hi/americas/4311957.st

Besley, T., \& Prat, A. (2006). Handcuffs for the grabbing hand? Media capture and government accountability. American Economic Review, 96(3), 720-736.

Bruce, G. (2010). The firm: The inside story of the Stasi. Oxford: Oxford University Press.

Brunetti, A., \& Weder, B. (2003). A free press is bad news for corruption. Journal of Public Economics, 87(7-8), 1801-1824.

Chowdhury, S. K. (2004). The effect of democracy and press freedom on corruption: An empirical test. Economics Letters, 85, 93-101.

Environmental Performance Index. (2014). Environmental performance index. Yale University. Retrieved December 10, 2014, from http://epi.yale.edu/

Freille, S., Haque, M. E., \& Kneller, R. (2007). A contribution to the empirics of press freedom and corruption. European Journal of Political Economy, 23(4), 838-862.

Gardner, R., \& Ostrom, E. (1991). Rules and games. Public Choice, 70(2), 121-149.

Haenen, I. (2014). Force \& marriage. Cambridge: Intersentia.

International Monetary Fund. (2012). New Setbacks, further policy action needed, July 2012. IMF World Economic Outlook (WEO) Update. Retrieved December 15, 2014, from http://www.imf.org/external/pubs/ft/weo/2012/update/02/index.htm

ISO. (January, 2013). The ISO Survey. The International Organization for Standardization. Retrieved December 10, 2014, from http://www.iso.org/iso/home/standards/certification/iso-survey.htm?certificate=ISO 9001\&countrycode=AF

Lancaster, T. D. (2014). Political monitoring as an analytical concept: A lasting legacy? Publius: The Journal of Federalism, 44 (2), 249-274.

Lancaster, T. D., \& Montinola, G. R. (1997). Toward a methodology for the comparative study of political corruption. Crime, Law and Social Change, 27(3-4), 185-206.

Lancaster, T. D., \& Montinola, G. R. (2001). Comparative political corruption: Issues regarding operationalization and measurement. Studies in Comparative International Development, 36, 3-8.

McCubbins, M., \& Schartz, T. (1984). Congressional oversight overlook: Police Patrols versus fire alarms. American Journal of Political Science, 28(1),165-179. 
Miller, J. A. (1987). Jeremy Bentham's panoptic device. ( R. Miller Trans.). October, 41(1), 3-29.

Neumayer, E., \& Perkins, R. (2004). What explains the uneven take-up of ISO 14001 at the global level? A panel-data analysis. Environment and Planning A, 36(5), 835.

NJ.com. (2014). East orange murder rate falls 73 percent, officials credit technology. Retrieved December 12, 2014, from http://nj.com/essex.index.ssf/2014/11/as_crime_rate_continues_to_drop_east_orange_credits_its_embrace_of_tech.html

Norris, P. (2012). Making democratic governance work: How regimes shape prosperity, welfare, and peace. Cambridge: Cambridge University Press.

Nytimes.com. (2014). Camden turns around with new police force. Retrieved December 10, 2014, from http://www.nytimes.com/2014/09/01/nyregion/camden-turns-around-with-new-police-force.html?_r=0

OECD. (January, 2013). FDI flows by partner country. OECD. Stat Extracts. Paris: The organization for economic co-operation and development. $\quad$ Retrieved $\quad$ December $\quad 10, \quad$ 2014, from http://stats.oecd.org/Index.aspx?DataSetCode=FDI_FLOW_PARTNER

Ostrom, E. (1990). Governing the commons: The evolution of institutions for collective action. Cambridge: Cambridge University Press.

Ostrom, E., \& Walker, J. (Eds). (2003). Trust and reciprocity: Interdisciplinary lessons from experimental research. New York: Russell Sage Foundation.

The Carter Center. (2014). Democracy. Retrieved December 10, 2014, from http://www.cartercenter.org/countries/activities_democracy.html

Transparency International. (2014). Transparency international: The global anti-corruption coalition. Retrieved November 21, 2014, from http://www.transparency.org/

US Environmental Protection Agency. (2013). Environmental management systems (EMS). Retrieved November 7, 2014, http://www.epa.gov/ems/\#iso14001

World Bank. (2014). GDP (current US\$). Data: GDP (current US\$). Retrieved December 15, 2014, from http://data.worldbank.org/indicator/NY.GDP.MKTP.CD 